\title{
A produção de vídeos como materiais didáticos para ensino de Libras como segunda língua
}

\author{
The production of videos as teaching materials to teach Libras as a \\ second language
}

\author{
Thaís Rafaela de Carvalho 1 \\ Ana Luisa Borba Gediel 2
}

\begin{abstract}
Resumo
Este relato tem como objetivo apresentar uma experiência vivenciada no Curso de Extensão em Língua Brasileira de Sinais (CELIB) de uma Instituição de Ensino Superior da Zona da Mata Mineira. O CELIB é um projeto de extensão criado em 2011, que oferece cursos de Libras em diferentes níveis para ouvintes e surdos da comunidade universitária e região. A Libras é uma língua que se organiza suas representações visuais no espaço, entretanto, há uma escassez de materiais didáticos eficientes para seu ensino. Sendo assim, o intuito desse texto é exibir, analisar e discutir alguns vídeos produzidos como materiais didáticos para o ensino de Libras como segunda língua no CELIB. A partir dessas considerações foi possível refletir na aplicabilidade dessa ferramenta no contexto de ensino e como essa tecnologia visual alcança as peculiaridades da Libras.
\end{abstract}

Palavras-chave: Libras. Vídeo. Ensino de segunda língua.

\begin{abstract}
This report aims to present an experience lived in the Extension Course in Brazilian Sign Language (CELIB) of a Higher Education Institution of the Zona da Mata Mineira. CELIB is an extension project created in 2011, that offers courses in Libras at different levels for listeners and deaf people from the university community and region. Libras is a language that organizes its visual representations in space, however, there is a shortage of effective teaching materials for their teaching. Therefore, the purpose of this text is to display, analyze and discuss some videos produced as teaching materials for teaching Libras as a second language in CELIB. From these considerations it was possible to reflect on the applicability of this tool in the teaching context and how this visual technology reaches the peculiarities of Libras.
\end{abstract}

Keywords: Libras. Video. Second language teaching.

\section{Introdução}

A Língua Brasileira de Sinais (Libras) é a língua própria da comunidade surda brasileira, sendo reconhecida legalmente através da Lei $n^{0} 10.436$, de 24 de abril de 2002 (BRASIL, 2002). Essa Lei foi regulamentada pelo Decreto $n^{0} 5.626$, de 22 de dezembro de 2005 (BRASIL, 2005), e foi a partir dessa data que a disciplina de Libras tornou obrigatória nos cursos de licenciatura, fonoaudiologia e formação de professores. Tais documentos legais tornam visíveis a Língua Brasileira de Sinais, bem como as suas especificidades linguísticas e culturais que permeiam pelo viés do ensino e aprendizagem da língua.

\footnotetext{
1 Graduanda em Letras. Universidade Federal de Viçosa (UFV) - Campus Viçosa Orcid: https://orcid.org/0000-0002-04170088. E-mail: thaisraffaelac@gmail.com

${ }_{2}^{2}$ Doutora em Antropologia Social. Universidade Federal de Viçosa (UFV) - Campus Viçosa. Orcid: https://orcid.org/00000001-5755-2592. E-mail: ana.gedielufv@gmail.com
}

LínguaTec, Instituto Federal de Educação, Ciência e Tecnologia do Rio Grande do Sul, Bento Gonçalves v. 5 , n. 2, p. 310-323, nov. 2020 . 
É portanto, nesse cenário de reconhecimento e valorização da Libras e sobretudo com 0 aumento da demanda por cursos para seu ensino, que surge em 2011 o Curso de Extensão em Língua Brasileira de Sinais (CELIB), projeto de extensão vinculado à uma Universidade da Zona da Mata Mineira e pertencente ao Departamento de Letras da referida instituição, com a proposta de oferecer à comunidade universitária e da região cursos regulares de Libras.

O foco principal da iniciativa do projeto de extensão é propiciar aos alunos dos cursos de licenciatura a oportunidade de atuar nas salas de aula do CELIB como professores estagiários de Libras. Em vista disso, há um processo de formação inicial para que os mesmos, tenham condições de integrar a prática da Libras com as discussões teóricas, além da capacitação orientada para o planejamento de aulas e para a elaboração de materiais didáticos. 0 segundo objetivo está voltado para os processos de ensino e aprendizagem da língua no formato de cursos extensivos. Para isso, são oferecidas duas modalidades de cursos, sendo uma delas para pessoas Surdas, a partir de uma perspectiva de ensino de primeira língua (L1)3; e, outra, para a comunidade em geral, levando em conta a perspectiva de segunda língua (L2). Desde o início das atividades didáticas do CELIB, há uma busca dos professores que já atuam na rede de ensino por formação continuada, desse modo, no conteúdo é organizado em uma estrutura que relaciona a teoria e prática sobre a cultura e a identidade surda, na tentativa de promover uma educação inclusiva.

Para que os objetivos sejam cumpridos, os cursos do CELIB de ensino de Libras como L1 para surdos e L2 para ouvintes são oferecidos semestralmente. Levando em consideração as perspectivas de utilização do quadro comum europeu para as línguas de sinais (LEESON et al., 2016), o CELIB está estruturado em níveis básicos, intermediários e avançados.

A maioria dos participantes dos cursos do CELIB são ouvintes, o que gera o desafio de possibilitar o ensino e aprendizagem ${ }^{4}$ para pessoas que têm como referência uma modalidade linguística diferente, ou seja, a modalidade vocal-auditiva no caso da Língua Portuguesa e a modalidade gestualvisual, nos casos das Línguas de Sinais (RODRIGUES, 2018). Dessa forma, se nas línguas vocais 0 mundo é narrado pelo som reproduzido pelo aparelho fono-articulatório, na Libras esse mesmo mundo é expresso pelos sinais visuais reproduzidos no espaço. Essa diferença nas modalidades linguísticas interfere diretamente nas metodologias de ensino.

\footnotetext{
${ }^{3}$ Conforme afirma Gesser (2010), a L1 é a língua materna do indivíduo e funciona como instrumento de socialização familiar. Por outro lado, a L2 é a língua usada para o convívio com a família, escolas ou comunidades linguísticas, podendo ser reconhecida oficialmente ou não pela sociedade que a envolve.

${ }^{4}$ De acordo com Silva e Delgado (2018) entende-se ensino e aprendizagem como uma relação entre professor e aluno, no qual ensinar e aprender são processos interdependentes. A escolha do termo justifica-se pelo fato de os vídeos apoiarem tanto o professor, no que diz respeito ao ensino quanto aos alunos, no que tange a aprendizagem.
} 
Em relação às metodologias para o ensino de línguas, no caso das línguas vocais há uma amplitude de atividades já elaboradas, como as descritas por Leffa (2003), que são elaboradas de acordo com o nível de conhecimento voltado para o conteúdo a ser desenvolvido. Entretanto, nem sempre essas atividades são compatíveis para o ensino das línguas de sinais em virtude das peculiaridades que essa língua possui. Sousa e Júnior (2016) apontam que para a produção de materiais didáticos para o ensino da Libras requer considerar as particularidades linguísticas dessa língua. Ainda, Lacerda et al. (2004) descrevem que para o ensino da Língua de Sinais como L2 devem ser levadas em consideração as especificidades culturais, necessitando de formação aprofundada e mais estudos na área.

$O$ avanço das tecnologias em meados do século XX permitiu consideráveis desenvolvimentos no âmbito educacional, adentrando à produção de materiais didáticos voltados para o ensino e aprendizagem de L2. Conforme afirma Gomes (2014), o professor deve reunir as competências das tecnologias e escolher a que the apresente mais eficaz para o cumprimento dos seus objetivos. A inserção de aparelhos celulares, projetores e outros dispositivos multimídias nas salas de aulas tem contribuído significativamente para o ensino de línguas. A utilização desses recursos, em especial o uso de vídeos, tem sido relevante, uma vez que se considera a Libras como uma língua visual-espacial, a filmagem se apresenta como a melhor alternativa para material didático.

Segundo Santos e Wielewicki (2017) a percepção dos termos como cultura e identidade Surda, "implica o entendimento de que ao sujeito surdo o mundo é mostrado antes de ser contado, o que não se justifica apenas pela forte relação entre os surdos e as tecnologias que facilitam a comunicação e registro de seus materiais, mas por ser a visualidade seu canal primeiro de significação" (SANTOS; WIELEWICKI, 2017, p.5). Dessa forma, a necessidade da elaboração de metodologias para o ensino da Libras como L2 englobando aspectos da cultura e identidades Surdas, assim como apontado por Lacerda et al. (2004), aproximam-se dessa perspectiva a partir do uso de tecnologias que priorizem a visualidade e a percepção dessa língua em uso. As mídias digitais, incluindo os dispositivos de interação e vídeos adentram essa questão.

Tendo em vista o contexto apresentado, este artigo tem o objetivo de apontar e discutir, por meio de um relato de experiência, dois vídeos em Libras elaborados e utilizados por uma professora do nível básico de ensino do CELIB, em seu primeiro módulo, durante o segundo semestre letivo do ano de 2019. A partir das contribuições das tecnologias voltadas para o ensino de línguas e para a formação de professores, a metodologia deste artigo foi baseada na produção de vídeos em Libras como material didático. A análise desse material produzido teve como base os estudos de Mayrink e Albuquerque-Costa (2017); Albuquerque-Costa e Mayrink (2020). Pretende-se aqui discorrer sobre a relação desses 
materiais e das especificidades linguísticas e culturais que compõem a comunidade surda e como o seu uso tem sido fundamental para um ensino que parte da abordagem comunicativa.

A organização do artigo está em tópicos, seguindo com a discussão sobre as particularidades linguísticas e culturais da Libras e indo ao encontro do uso das tecnologias e dos vídeos para a comunidade surda. Logo após, são descritos e analisados os dois vídeos, discorrendo sobre sua produção e reprodução no contexto das aulas, a partir da perspectiva da professora. Em um primeiro momento da análise, são evidenciadas as contribuições relativas ao formato e às adequações culturais; já no segundo tópico de análise, é apresentado um breve panorama referente ao gênero discursivo vídeo e sua visualização como material didático para o ensino de Libras como segunda língua. Por fim, algumas considerações acerca das potencialidades e desafios ligados a esse processo de criação e uso de vídeos para as aulas de Libras.

\section{Os materiais didáticos para o ensino de Libras como L2}

De acordo com Albres (2012), a aprovação das leis que reconhecem a Libras permitiu que o seu ensino sofresse grandes transformações, aumentando a demanda de cursos, de profissionais e da produção de materiais didáticos. Em decorrência da preocupação do governo com a formação de profissionais para atuarem nessa área, surgiram também cursos focados para esse objetivo. Todavia, conforme a autora supracitada, "a descrição das características linguísticas da língua é insuficiente e pouco se sabe das diferenças no ensino-aprendizagem por conta da modalidade visuo-gestual" (ALBRES, 2012, p.2).

A Libras apresenta algumas especificidades linguísticas e culturais diferentes em relação às línguas vocais, o que influencia intensamente no seu processo de ensino e aprendizagem. Como afirma Quadros (2009), a cultura surda é marcada por sujeitos que se relacionam com o mundo por meio do visual, utilizando do espaço para compor sua comunicação. Por conta da diferença da modalidade, "0 uso de métodos desenvolvidos primeiramente para o ensino de línguas orais-auditivas precisa de investigação sobre sua aplicabilidade no ensino de línguas de modalidade visuo-gestual" (ALBRES, 2012, p.2).

No que tange os materiais didáticos para o ensino da Libras como segunda língua, Santos (2014) aponta que "é escasso o acesso a materiais didáticos tanto de suporte tradicionais como aqueles disponíveis na internet, diferente do que acontece com a maior parte das línguas estrangeiras orais que já têm material disponível para seus aprendizes a contento" (SANTOS, 2014, p.2). Entre os materiais 
encontrados estão as glosas, cartilhas e dicionários e que, por mais que apoiem parcialmente o ensino da Libras, são limitados na demonstração de alguns parâmetros que são muito importantes para a comunicação em Libras.

As cartilhas para ensino da Libras para ouvintes foram usadas como recursos didáticos por muito tempo. "Historicamente a apresentação lexicográfica da Libras foi uma das poucas estratégias de ensino desenvolvidas para o seu ensino, que consistia na simples reprodução dos grupos de palavras das cartilhas de Libras impressas (fotocopiadas)" (SANTOS, 2014, p.5). Os métodos de ensino da Libras por meio deste recurso consistem em conhecer a cada aula os sinais de uma determinada categoria semântica, como família, alimentos, profissões e outros. $O$ professor sinalizava esses sinais e solicitava aos alunos a reprodução daquilo que foi sinalizado, não desenvolvendo com 0 grupo a função comunicativa da língua.

Sem o desenvolvimento da função comunicativa é evidente que o modelo de ensino não é produtivo, já que conforme afirma Gesser (2010) "a lingua(gem) é concebida como instrumento de comunicação e interação social. Os indivíduos são partícipes na construção discursiva e de maneira sempre negociada buscam a compreensão mútua que vai além da simples decodificação linguística" (GESSER, 2010, p.7). Portanto, torna-se importante que o ensino da Libras vá além da simples exposição à uma quantidade de sinais com seus respectivos significados, e, que sobretudo, ofereça oportunidades ao aprendiz para o desenvolvimento da habilidade comunicativa a fim torná-lo usuário da língua.

Além da competência comunicativa, alguns dos parâmetros fonológicos da Libras como as expressões faciais e o movimento são inatingíveis quando se utiliza tais recursos. De acordo com Lebedeff e Santos (2014) muitas cartilhas utilizam de flechas para indicar a direção dos sinais e de pontilhados para orientar o movimento, porém, essas informações não são claras e nem precisas acarretando ainda mais dificuldades durante o processo de aprendizagem dessa língua.

Nessa perspectiva, observa-se que o grande desafio para os professores de Libras é, segundo Albres (2012), a produção de materiais didáticos que contemplem os elementos linguísticos da Libras, mas que também inclua a língua a partir de contextos comunicativos. 0 que se percebe como consequência desse desafio é que muitas das vezes a língua de sinais é entendida como inferior em relação às línguas orais, portanto, Pereira (2009) sugere que haja uma reflexão maior acerca dos materiais didáticos para o ensino de Libras.

\section{A tecnologia e o ensino de Libras}

LínguaTec, Instituto Federal de Educação, Ciência e Tecnologia do Rio Grande do Sul, Bento Gonçalves 
O avanço das tecnologias transformou diversos aspectos no estilo de vida humano, desconstruindo barreiras culturais e geográficas e "propiciando, por exemplo, o aparecimento de novos grupos ou transformando os que já existiam antes" (SANTOS; WIELEWICKI, 2017, p.3). Conforme assinala Lopes (2017), para a comunidade surda as novas tecnologias são acessíveis a comunicação visual, visto que a Libras é uma língua com característica gesto-visual.

Santos e Wielewicki (2017) apontam que com a difusão de equipamentos como as câmeras filmadoras, a produção e reprodução de sinalização da Libras em vídeo, que antigamente só poderia ser sinalizada presencialmente, se intensificou. Segundo as autoras Rosa e Klein (2011), "a expansão dessas tecnologias cria condições e possibilidades de os surdos compartilharem suas experiências, de estabelecerem espaços de construção de significados sobre o ser surdo utilizando-se das diversas mídias, postando histórias, anedotas, informações das mais diversas" (ROSA; KLEIN, 2011, p.93).

No que tange o ensino de Libras como segunda língua, os recursos tecnológicos "vêm contribuindo para o processo de difusão do ensino de LIBRAS" (ROCHA et al., 2018, p.2). Para Pimentel et al. (2018), a inserção de suportes tecnológicos na construção do conhecimento é importante, pois se trata de escolher e eleger alternativas que cumpram determinadas necessidades requeridas no processo de ensino e aprendizagem.

Nesse sentido, "considerando que a Libras é uma língua visual-espacial, o material didático mais adequado é aquele que se apresenta em formato de filmagem" (SANTOS, 2014, p.3). Os vídeos são instrumentos de fácil acesso e entendimento, o que "possibilita captar os diferentes parâmetros que compõem os sinais e a sua sequencialidade" (LEDEBEFF; SANTOS, 2014, p.11). Além disso, Ledebeff e Santos (2014) salientam que apenas recursos visuais que reproduzem as antigas cartilhas impressas não são necessários para a imersão das práticas sociais, sendo necessário portanto, vídeos roteirizados que priorizam a proposta comunicativa.

Arroio e Giordan (2006) apontam que os vídeos são importantes aparatos que permitem experiências sensoriais ligadas ao visível, destarte, segundo os autores "o produto audiovisual pode ser utilizado como motivador da aprendizagem e organizador do ensino na sala de aula" (ARROIO; GIORGAN, 2006, p. 9). Desde modo, "é recomendável ao professor de língua de sinais estar atento às mudanças atuais e se adequar às novas formas e linguagens alternativas disponíveis, como a utilização do vídeo como componente avaliativo dentro da disciplina de Libras" (ALBUQUERQUE et al., 2019, p.5). Em conformidade com o que afirma Pimentel et al. (2018), o emprego de bons materiais didáticos é importante para a transmissão do conhecimento e a produção adequada às necessidades do públicoalvo é primordial. 


\section{As contribuições dos vídeos para o ensino de Libras}

Reconhecendo que a Libras é uma língua que se organiza no espaço por meio das representações visuais, é importante considerar tais peculiaridades linguísticas e culturais na produção de materiais didáticos. A utilização de vídeos tem sido a proposta de melhores resultados, já que o registro de histórias, piadas e diálogos contados em Libras produz um recurso didático "através da qual os alunos poderão estudar em casa os conteúdos aprendidos em sala de aula com autonomia e de forma lúdica" (SANTOS, 2014, p.6).

Para o ensino de Libras no CELIB os vídeos têm sido importantes ferramentas de aprendizagem, juntamente com diálogos e jogos didáticos que permitem a interação dos alunos. Conforme é proposto na ementa do curso, as aulas devem abordar alguns temas seguindo as necessidades de cada nível. Para isso, o professor deve apropriar-se dos vídeos e adequá-lo para os objetivos que se deseja cumprir.

Os vídeos que aqui são apresentados foram usados como aparatos didáticos nas aulas de Libras do nível básico no seu primeiro módulo, os quais foram elaborados pela professora. Eles foram produzidos para os alunos que estão iniciando os estudos de Libras e ainda não possuem o domínio linguístico. Além disso, apresentam as temáticas introdutórias que foram sugeridas pela ementa do nível e se dispõem de diferentes intervenções pedagógicas.

Os materiais produzidos foram armazenados e compartilhados em uma pasta no dispositivo digital gratuito Google Drive, permitindo que os alunos pudessem assisti-los novamente. É importante ainda destacar que a produção desses é feita de forma simples, sem edições ou legendas em português, pois o foco principal é servir como ferramentas para o cumprimento de outros objetivos didáticos.

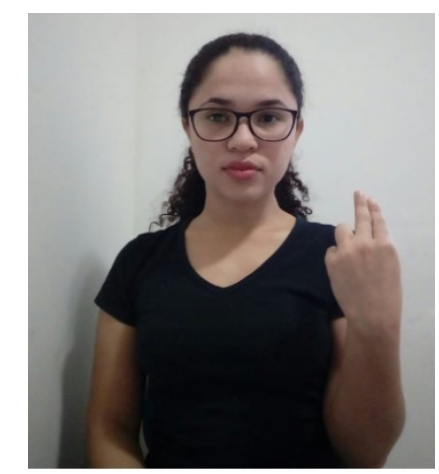

Figura 1. Vídeo de apresentação pessoal. Fonte: Elaborado pelos autores. 
A Figura 1 representa o primeiro vídeo, em específico o sinal "MEU NOME É", e foi utilizado para introduzir a aula com o tema "Apresentação Pessoal". Para isso foi elaborado um roteiro breve de apresentação pessoal que incluía alguns sinais básicos em Libras como: "BOM DIA", "BOA TARDE" ou "BOA NOITE"; "MEU NOME É"; "MINHA IDADE É", "MORO NA CIDADE". Depois de elaborado o roteiro, foi realizada a gravação do vídeo pela professora da turma, que se atentou para as orientações quanto aos adereços e vestimentas utilizadas bem como ao cenário disposto para a produção.

Após ser gravado, a exibição do material visual foi realizada na sala de aula e foi dividida em alguns momentos, considerando o ciclo do modelo A-P-P descrito por Richards (2006). Nesse modelo, a aula é organizada em três estágios: no primeiro ocorre a apresentação das estruturas gramaticais; no segundo, é desenvolvida a prática controlada com a indicação de frases a serem realizadas e passa para a menos controlada, com a criação e elaboração de frases a partir dos modelos apresentados. E, por último, o professor propõe atividades para os alunos desenvolverem de forma mais livre, por exemplo, com a criação de diálogos. Acredita-se que através desse ciclo o aluno é capaz de compreender melhor o que lhe é ensinado, uma vez que a divisão em estágios facilita o entendimento e o aprendizado.

Levando em conta o modelo de Richards (2006), o primeiro vídeo foi reproduzido no primeiro estágio (apresentação) sem traduções para o português, dando ênfase na contextualização do conteúdo e no primeiro contato dos alunos com o tema proposto da aula. Logo após esse primeiro contato o vídeo foi reproduzido uma segunda vez (prática), para realizar as traduções dos sinais não identificados pelos alunos e para que esses pudessem praticar os sinais traduzidos. Por fim, foi realizado o terceiro estágio (produção), no qual o vídeo foi utilizado como modelo para produção um diálogo livre que contemplasse os sinais aprendidos na aula.

A utilização dos vídeos seguindo esse modelo, permitiu ainda o desenvolvimento do método comunicativo da língua. Esse método surgiu nos anos 60 e 70 na Inglaterra e foi embasado em trabalhos como os de Michael Halliday. Tal abordagem começa a ser mais humanista e enfatizar o processo interativo da língua. De acordo com Almeida Filho (1998) apud Gesser (2010), os cursos que foram desenvolvidos a partir dessa abordagem passaram a dar mais enfoque aos sistemas necessários para 0 uso comunicativo e não mais para os aspectos lexicais e gramaticais da língua.

Nesse sentido, a língua passa a ser utilizada para realizar algumas ações como pedidos, troca de informações, apresentações, entre outras tarefas comunicativas. Assim como afirma Gesser (2010), sobre a inserção do método comunicativo

a língua passa a ser concebida para além de um simples processo de codificação e decodificação, destacando os professores e alunos como agentes ativos, que se engajam no processo ensino-aprendizagem através de atividades de negociação e construção de sentidos, 
e que dá vazão, portanto, à produção criativa, imprevisível e singular da natureza interacional. (GESSER, 2010, p.23)

A partir das considerações de Gesser (2010), sobre o engajamento de agentes ativos ao processo foi elaborado um vídeo com a descrição de uma tarde no zoológico, conforme figura ilustrativa que segue:

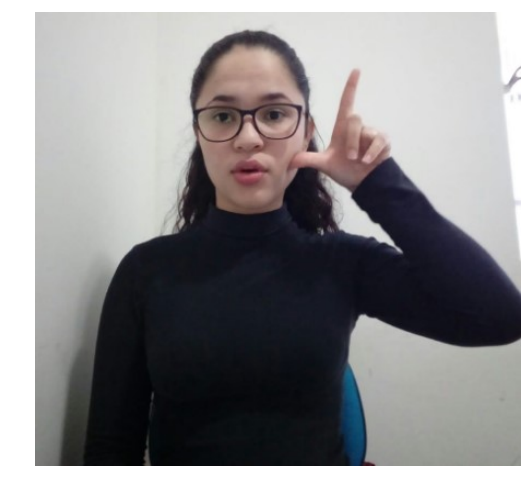

Figura 2. Vídeo tarde no zoológico.

Fonte: Elaborado pelos autores.

A Figura 2 representa o sinal da palavra "ONTEM", foi utilizado como material didático em uma aula sobre "Classificadores". De acordo com Pizzio et al. (2009), o classificador é um tipo de morfema que pode ser ligado a um sinal para representar a classe ao qual esse sinal pertence, bem como para descrevê-lo quanto à forma, tamanho e ação verbal. Em outras palavras, o classificador é um recurso que torna a sinalização mais clara, principalmente se essa for destinada a ouvintes. Nessa aula, foram explicadas as definições dos classificadores por meio do vídeo que tinha a temática a "Tarde no zoológico". Essa criação teve como objetivo contar uma história que incluía alguns classificadores de animais, objetos e pessoas.

A exibição desse vídeo também ocorreu em momentos, conforme o ciclo A-P-P proposto por Richards (2006), comentado anteriormente. No primeiro estágio nomeado pelo autor como apresentação, os alunos foram apresentados ao vídeo totalmente em Libras e sem traduções, visando novamente 0 primeiro contato com a sinalização do tema proposto para a aula. No segundo instante, no estágio da prática, o vídeo foi reproduzido novamente entre pausas para a realização da tradução pelos alunos que em sequência repetiam os sinais apresentados.

Depois de terem compreendido toda a sinalização foi desenvolvido o último estágio do ciclo, que consistia na realização de uma atividade de fixação. Os alunos deveriam assistir ao vídeo novamente e produzir um quadro separando os classificadores utilizados, especificando-os quanto ao tipo, de acordo com o que foi explicado na aula. 
Em vista do que foi discutido nos parágrafos anteriores deste subtópico, é possível perceber que os vídeos utilizados como aparatos didáticos contribuem significativamente para 0 ensino e aprendizagem da Libras. As filmagens são capazes de captar com clareza alguns aspectos que nos materiais impressos não são aperfeiçoados. Além disso, ao simularem contextos reais de comunicação, o material visual expande seu conteúdo para além do lexical, oferecendo oportunidades para 0 desenvolvimento comunicacional da língua.

\section{0 uso do gênero discursivo vídeo para o ensino da Libras como L2}

De acordo com Bakhtin (2000), a comunicação humana se efetua por meio de enunciados que refletem as intenções específicas do que se deseja transmitir; e, esses enunciados são denominados por ele como gêneros do discurso. Dialogando com as ideias desse autor, Marcuschi (2002) também apresenta o ponto de vista de que a língua faz parte de um processo social regido pelo gênero textual e, além disso, aponta que os gêneros textuais são fenômenos históricos ligados à vida cultural e social.

Com 0 advento das tecnologias novas formas de comunicação foram surgindo e consequentemente, gêneros textuais são apresentados. Dentro desses gêneros destaca-se o vídeo, que além de ser um meio favorável para a comunicação, tem sido como um excelente material didático para 0 ensino de Libras como L2. Pimenta et al. (2018) afirma que o vídeo é uma ferramenta que pode ser inserida de forma eficiente no contexto educacional, uma vez que desperta no aluno a atitude de compreensão e recepção, desenvolvendo a percepção visual e lógica.

A disposição desse recurso visual também é descrito por Ferrés (1996), mencionando que um bom vídeo pode ter diversas funções como introduzir um conteúdo, despertar a curiosidade e motivar a aprendizagem de novos temas. Nessa perspectiva, é possível perceber que os vídeos têm várias finalidades e que essa pluralidade de funções favorece para a sua avaliação como material didático.

Quando se discute sobre a essência dos materiais didáticos, Gomes (2008) sugere ser didático aquilo que apoia a realização de outras atividades. Ao atribuir essa significação aos vídeos, percebe-se que sua aplicabilidade não está em somente ser exibido na sala de aula, mas em introduzir ou auxiliar outras ações. Isto posto, pretende-se aqui analisar e discutir como o gênero vídeo pode ser considerado material didático para o ensino de Libras, tomando como exemplo os dois materiais visuais anteriores apresentados.

O primeiro vídeo representado pela Figura 1, como já dito anteriormente, foi utilizado para introduzir uma aula sobre "Apresentação pessoal". Após ser apresentado para a turma e serem desenvolvidas as atividades a partir da sua exibição, o material serviu como modelo para uma atividade 
posterior em que os alunos teriam que gravar um vídeo semelhante, realizando a sua apresentação pessoal. Arroio e Giordan (2006) descrevem esse tipo de vídeo como vídeo-motivador, uma vez que é usado para fomentar uma atividade posterior. O uso de vídeos com o intuito de sustentar outra ação é algo considerável, pois a apresentação de uma referência torna a realização da atividade mais clara, desenvolvendo o processo de aprendizado.

O segundo vídeo, representado pela Figura 2, foi aplicado em uma aula sobre "Classificadores" e a partir de sua exibição foi proposto aos alunos que assistissem ao vídeo novamente, e selecionassem os classificadores que foram sinalizados no vídeo. De acordo com Arroio e Giorgan (2006), a funcionalidade desses vídeos está em servir como material investigativo, uma vez que promove questionamentos e fortalece a explicação do professor. Diante disso, a disposição desse tipo de vídeo promove ainda um ensino e aprendizado produtivo, já que questionamentos e induções são muito importantes nesse processo.

É possível perceber que os vídeos podem servir de apoio para diferentes atividades e consequentemente cumprir diferentes objetivos. Nas aulas do CELIB em especial, o gênero vídeo é constantemente empregado com finalidades que variam segundo níveis, temas e atividades que se desejam realizar. Sendo assim, é sempre aconselhável que os professores estejam atentos aos objetivos dos materiais didáticos, visando que eles realmente auxiliem no processo de ensino e aprendizado da Libras.

\section{Considerações finais}

Nota-se que 0 avanço da tecnologia e a popularização dos aparelhos digitais permitiu que os métodos de ensinos tornassem mais inovadores e significativos. Neste relato, enfatizamos o uso dessas tecnologias na confecção de vídeos para o ensino de Libras como segunda língua para ouvintes no Curso de Extensão em Língua Brasileira de Sinais (CELIB).

Ainda destacamos que esses vídeos são importantes ferramentas que abrangem as peculiaridades da Libras, que em materiais didáticos tradicionais não são apresentados com clareza. Demos ênfase na utilização desses aparatos na promoção do ensino da língua de sinais em seu contexto de uso, ou seja, pela abordagem comunicativa.

Os materiais que se encontram disponíveis para o ensino de Libras como segunda língua são em sua grande maioria limitados. Muitos não abordam o contexto comunicativo, sendo reduzidos apenas a demonstração do sinal e do seu significado no português. Como um curso de Libras que comporta em 
grande parte alunos ouvintes, o CELIB busca o diferencial ao propor a produção de materiais didáticos que atendam para o método de ensino de língua comunicativo.

Para mais, é importante destacar que por ser um curso de extensão cujo o objetivo principal é oferecer a formação inicial e continuada de professores para a atuação no ensino de surdos, infere-se que o uso de tais materiais também contribui para o oferecimento de uma educação acessível aos surdos por parte de tais professores. Ao entrarem em contato com objetos de aprendizagem que exploram as habilidades visuais, os professores que já atuam na rede de ensino e até mesmo os que futuramente irão atuar, percebem a importância em adaptar o material pedagógico conforme as especificidades e necessidades do aluno.

Portanto, depreende-se que o uso do vídeo como material didático no ensino de Libras como L2 promove uma aprendizagem significativa da língua, além de tornar os alunos mais reflexivos acerca da importância dos aspectos visuais para a cultura surda. Ademais, considera-se oportuna a elaboração de pesquisas e artigos que abordam essa temática, tendo em vista que Língua Brasileira de Sinais, por mais que tenha conseguido seu reconhecimento na sociedade, ainda precisa trilhar um caminho que abranja espaços de divulgação dessa língua e sua importância condizente as línguas orais.

\section{Referências}

ALBRES, N. A. Ensino de Libras como segunda língua e as formas de registrar uma língua visuo-gestual: problematizando a questão. ReVEL, v. 10, n. 19, 2012. Disponível em $<$ http://www.revel.inf.br/files/6e9e138e1df0292c48e355324465cb64.pdf>. Acesso em: 21 de setembro de 2020.

ALBUQUERQUE-COSTA, H; MAYRINK, M. F; OLIVEIRA, R. D. de. Repensando a relação entre metodologia, tecnologia e formação docente no ensino de línguas. Revista Intercâmbio, v. XLV: 187-212, 2020. Disponível em<https://revistas.pucsp.br/index.php/intercambio/article/view/50454/3297>. Acesso em: 21 de setembro de 2020.

ARROIO, A.; GIORDAN. O vídeo educativo: aspectos da organização do ensino. Química nova escola, v. 24, n.1, p. 8-11, 2006. Disponível <http://www.lapeq.fe.usp.br/megvt/disciplina/biblioteca/artigos/arroio_giordan.pdf $>$. Acesso em: 23 de julho de 2020.

BAKHTIN, M. (2000). Os gêneros do discurso. In: M. Bakhtin. Estética da criação verbal. São Paulo: Martins Fontes, 2000.

BRASIL. Decreto $n^{0} 5626$ de 22 de dezembro de 2005. Regulamenta a Lei $n^{0} 10.436$, de 24 de abril de 2002, que dispõe sobre a Língua Brasileira de Sinais - Libras, e 0 art. 18 da Lei $n^{0}$ 10.098, de 19 de dezembro de 2000.2 Disponível em $<$ https://www.udesc.br/arquivos/udesc/documentos/Lei_n_10_436_de_24_de_abril_de_2002_15226 896225947_7091.pdf>. Acesso em: 20 julho. 2020. 
BRASIL. Lei n 10436 de 24 de abril de 2002. Dispõe sobre a Língua Brasileira de Sinais - Libras e dá outras providências. Brasil: Planalto, (2002). Disponível em <http://portal.mec.gov.br/arquivos/pdf/lei10436.pdf>. Acesso em: 20 julho.2020.

CANI, J. B; SANTIAGO, M. E. V. O papel do quadro comum europeu de referência para idiomas: aprendizagem, ensino e avaliação (QCER) na internacionalização das IES: uma análise sob a perspectiva do Letramento Crítico e dos Multiletramentos. Trabalhos em Linguística Aplicada, v. 57, n. 2, p. 1164-1188, 2018. http://dx.doi.org/10.1590/010318138650002297941

DE ALBUQUERQUE, T. R; RODRIGUES, K. C; RODRIGUEZ, E. A. V. LIBRAS na formação de professores: 0 vídeo como ferramenta de avaliação da aprendizagem. Revista Educação, Artes e Inclusão, v. 15, n. 1, p. 217-245, 2019. https://doi.org/10.5965/1984317815012019217

DE LACERDA, C. B. F; CAPORALI, S. A; LODI, A. C. Questões preliminares sobre o ensino de língua de sinais a ouvintes: reflexões sobre a prática. Distúrbios da Comunicação, v. 16, n. 1, 2004. Disponível em <https://revistas.pucsp.br/index.php/dic/article/view/11620>. Acesso em: 21 de setembro de 2020.

DE SOUZA, A. L. S; JÚNIOR, J. T. O uso de tecnologias (TIC) na produção de material didático bilíngue libras/português na Universidade Federal de Viçosa. In: Revista Forum. 2016. http://dx.doi.org/10.20395/fb.v0i33.58

FERRES, J. Vídeo e Educação. 2 a ed., Porto Alegre, Artes Médicas, 1996.

GESSER, A. Libras, que língua é essa? Crenças e preconceitos em torno da língua de sinais e da realidade surda. Parábola Ed., 2009.

GESSER, A. Metodologia de ensino em Libras como L2. Florianópolis: Ed. UFSC, 2010.

GOMES, L. Vídeos didáticos: uma proposta de critérios para análise. Revista Brasileira de Estudos Pedagógicos, v. 89, n. 223, 2008. http://dx.doi.org/10.24109/2176-6681.rbep.89i223.688 .

LEBEDEFF, T. B; SANTOS, A. N. dos. Objetos de aprendizagem para o ensino de línguas: vídeos de curta-metragem e o ensino de Libras. Revista Brasileira de Linguística Aplicada, v. 14, n. 4, p. 1073-1094, 2014.https://doi.org/10.1590/S1984-63982014005000020.

LEESON, L; VENTURI, L. A review of literature and international practice on national and voluntary registers for sign language interpreters. Dublin: Sign Language Interpreting Service, 2017.

LEFFA, Vilson J. Como produzir materiais para o ensino de línguas. Produção de materiais de ensino: teoria e prática. Pelotas: EDUCAT, p. 13-38, 2003.

LOPES, G. K. F. O uso das tecnologias no processo de ensino e de aprendizagem do surdo": Libras em educação a distância. Revista Virtual de Cultura Surda. Rio de Janeiro: Editora Arara Azul, edição, n. 20, 2017. Disponível em: <https://editora-arara-azul.com.br/site/admin/ckfinder/userfiles/files>. Acesso em: 21 de setembro de 2020.

MARCUSCHI, L. A. (2002). Gêneros textuais: definição e funcionalidade. In: A. P. D. et al (org.). Gêneros textuais e ensino. Rio de Janeiro: Lucerna, 2002. 
MAYRINK, M. F. ; Albuquerque-Costa, Heloisa B. . Ensino presencial e virtual em sintonia na formação em línguas estrangeiras. THE ESPECIALIST (PUCSP), v. 38, p. 1-14, 2017. Disponível em $<$ https://revistas.pucsp.br/index.php/esp/article/view/32218/22253>. Acesso em: 21 de setembro de 2020.

PEREIRA, M. C. P. A língua de sinais brasileira: análise de material didático de ensino como segunda língua para ouvintes. Revista Linguasagem, v. 7, n. 1, 2009. Disponível em $<$ http://www.linguasagem.ufscar.br/index.php/linguasagem/article/view/557> . Acesso em: 23 de julho de 2020.

PIMENTEL, K. S. et al. Produção e Avaliação de Vídeos em Libras para Educação em Saúde. Revista Educação Especial, v. 31, n. 60, p. 181-195, 2018. https://doi.org/10.5902/1984686X24101.

QUADROS, R. M.; CRUZ, C. R. Língua de sinais. Artmed Editora, 2009.

RICHARDS, J. C. O ensino comunicativo de língua estrangeira. São Paulo: SBS Editora, 2006.

ROCHA, Paul Symon Ribeiro; DE LIMA, Rommel Wladimir; QUEIROZ, Paulo Gabriel Gadelha. Tecnologias para o ensino da Língua Brasileira de Sinais (LIBRAS): Uma revisão sistemática da literatura. Revista Brasileira de Informática na Educação, v. 26, n. 03, p. 42, 2018. https://doi.org/10.5753/rbie.2018.26.03.42

RODRIGUES, Carlos Henrique. Tradução e Língua de Sinais: a modalidade gestual-visual em destaque. Cadernos de Tradução, v. 38, n. 2, p. 294-319, 2018. https://doi.org/10.5007/2175-7968.2018v38n2p294

ROSA, F. S.; KLEIN, M. O que sinalizam os professores surdos sobre literatura surda em livros digitais. In: KARNOPP, K.; KLEIN, M.; LUNARDI-LAZZARIN, M. L. (Org.) Cultura Surda na contemporaneidade: negociações, intercorrências e provocações. Canoas: Ed. Da ULBRA, 2011, p. 91-112.

SANTOS, A. Libras na UFPEL: Experiência da produção de material didático para o ensino da Libras como L2 a partir da abordagem comunicativa. Isabel Maria Sabino de Farias; Maria Socorro Lucena Lima; Maria Marina Dias Cavalcante, p. 04150-04161. Disponível em: <http://www.uece.br/endipe2014/ebooks/livro2/>. Acesso em: 23 de julho. 2020.

SANTOS, C. C. G. dos; WIELEWICKI, V. H. G. Os cinco sentidos, tradução de Nelson Pimenta: reflexões sobre poesia surda no Youtube. FronteiraZ. Revista do Programa de Estudos Pós-Graduados em Literatura e Crítica Literária, n. 19, p. 146-162, 2017. https://doi.org/10.23925/1983-4373.2017i19p146$\underline{162 .}$

Data de submissão: 21/09/2020. Data de aprovação: 12/10/2020. 